\title{
Application and Innovation of BIM Technology in Construction Management Stage of Large Medical Construction Projects
}

\author{
Liu Zhen ${ }^{1}$ \\ ${ }^{1}$ Dalian Vocational \&Technical College, 116035
}

\begin{abstract}
Jinzhou New District Medical Center of the first Affiliated Hospital of Dalian Medical University is the largest medical construction project, which has a large volume, complex functions, and involves many construction majors. It also has many difficulties during construction processes and need to meet high quality requirements. Therefore, traditional construction methods are difficult to meet its design requirements. BIM technology is used in the project, to perform construction process simulation, to optimize construction organization and to control cost and quality. In fact, it is applied in the whole construction management, quality management, cost management and safety management, which leads to the great success in avoiding the problems of design defects, quality hazards and economic losses caused by the complicated process requirements of medical construction projects. The result shows that BIM technology has brought many benefits, such as some economic effect, the shortened construction period and the expected quality and safety objectives. That is to say, the application effect of BIM technology is remarkable.
\end{abstract}

\section{Introduction}

As a kind of special public construction project, hospitals have more stringent technological requirements than ordinary industrial and civil buildings, whose construction process and management are also more complicated. The traditional hospital construction project is mainly based on two-dimensional drawings to guide the construction, which leads to the frequent discovery of design defects in the construction stage, resulting in a large number of economic losses; in addition, a large number of construction personnel is not well equipped, sometimes the understanding of the design drawings is wrong, resulting in engineering quality problems.

In view of this, BIM technology is introduced into the hospital construction management stage because of its visualization, so as to minimize the design defects, make the engineering drawings more intuitive and easy to be understood, and then save the project cost greatly, improve the engineering quality, and provide the necessary data support for the later operation and maintenance. Application of BIM technology in the construction management stage of Jinzhou New District Medical Center in the First Affiliated Hospital of Dalian Medical University is introduced in this paper.

\section{Project Profile}

The project of Jinzhou New District Medical Center of the First Affiliated Hospital of Dalian Medical University has complex geological structure and high groundwater level. Its highest flood water level is $39.77 \mathrm{~m}$, while the absolute elevation of the construction area leveling point is only $41.5 \mathrm{~m}$; the construction land area is $23424 \mathrm{~m}^{2}$ and the total construction area is $203117 \mathrm{~m}^{2}$. There are 3 floors underground, with a construction area of $46,426 \mathrm{~m}^{2}$, of which the civil air defense project area is $11,818.99 \mathrm{~m}^{2}$; and also a 21-floor comprehesive building and a 13-floor teaching and research building above ground, whose construction area is respectively $132,417 \mathrm{~m}^{2}$ and $2,4274 \mathrm{~m}^{2}$. It is currently the largest medical project in the northern region. The overall plan of the project is shown in Figure 1 .

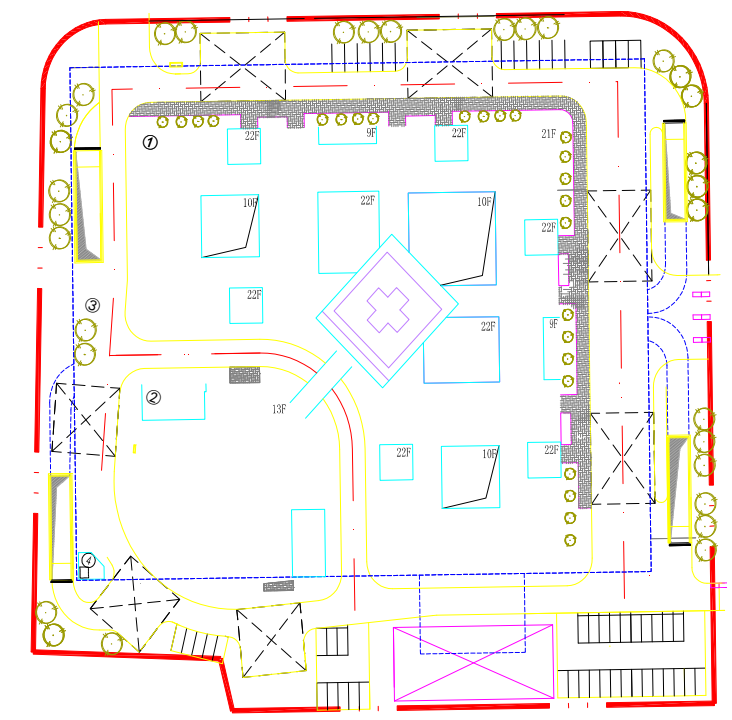

Fig 1. Project master plan

The project adopts fine decoration design, fire prevention, waterproof grade are all grade one; the underground garage of the project is equipped with 
exhaust ventilation device, noise reduction elevator and septic tank to meet the requirements of environmental protection; the mechanical and electrical installation works include water supply, drainage, strong electricity, weakness, central air conditioning system, ventilation system, heating and heating system, firefighting system and elevator, etc., of which only elevators include 19 human ladders and 3 fire ladders. Because of its large volume, complex functions, many specialties involved, high requirements and difficulty in construction, the traditional construction method is difficult to meet the design requirements, which urges the project to apply BIM technology.

\section{Analysis of key points and difficulties in construction management process}

\subsection{Difficulties and key points of construction organization}

(1) Tight construction period and a large amount of resource invested

A large number of basement floors, up to three underground, single-story area of about 1,5000 m.2The floor height varies and the height is large, the basement three-story structure floor height $8.7 \mathrm{~m}$; At the same time, the complex floor non-standard number of layers up to 10(including equipment layer), the single layer area of about $6800 \mathrm{~m}$.2The floor height is $5.9 \mathrm{~m}$ or $5.1 \mathrm{~m}$, Due to the tight construction period, it is difficult for the material tools to realize the turnover between flow sections, and a large amount of material tools need to be invested.

(2) Difficulties in organizing and transporting materials on site

The project construction site can use the site area is very small, the construction is very inconvenient. Only the east side and the north side of the site adjacent to the municipal road, the rest of the two sides near other construction sites, the off-site cannot form a loop, at the same time the west side of the enclosure from the edge of the foundation pit only slope distance, the field cannot form a loop, so the material approach management, concrete pouring arrangement requirements are high.

(3) Difficulties in planning and managing the general construction layout

The distance between the two towers of the project is close, which makes the arrangement of group towers difficult. Especially when the decoration and mechanical and electrical professional inserted one after another, the site into many professional synchronous crossconstruction peak stage, site coordination problems.

(4) More content of coordinated control of multiprofessional subcontracting

Project professional subcontracting, total package management coordination content. In addition to deepening the overall management of design, schedule, technology, quality, safety, cost, integrated affairs, completion acceptance and data, it is also responsible for the protection of finished products and the provision of temporary facilities on the spot, the provision of vertical transportation equipment, professional cross-coordination, etc. The responsibility of the general package is very large. At the same time, there are many kinds of medical equipment and instruments, and the quantity is large, so it is very important to do a good job of relevant installation and matching work.

\subsection{Difficulties of deepening design management}

The scale of the project is large and the building functions are complex. Dozens of professional projects such as curtain wall, electromechanical, fine decoration, landscaping, and medical special equipment need to be deepened design, so whether the deepening design can be completed in time will directly affect the conduct of related follow-up work.

At the same time, due to the limitation of professional engineering, it is very difficult for each professional unit to consider the other specialties associated with the joint, and the phenomenon of "professional fighting" often occurs in the construction stage.

In addition, this project is a Grade 3A hospital building, interior decoration and decoration project should provide a humanized and comfortable medical environment; meanwhile, it should also meet the special attributes of each functional division, and provide a safe and good diagnosis and treatment environment for medical personnel and patients. Decoration should meet the requirements of durability, humanistic care, green environmental protection and other special requirements.

\subsection{High requirements of construction quality management}

The quality goal of this project is to ensure that it wins the "Luban Award for China Construction Project". The project has a large volume, many medical rooms, a large number of terminal equipment for decoration and installation projects, a wide range of quality control points, and a large number of construction parties, which cause the general contractor a relatively heavy workload. Thus to win the Luban Award, the project quality excellence management workload is extremely It is arduous and must be carried out continuously and efficiently.

\subsection{High requirements for safe production and civilized construction management}

There are many basements and above-ground floors in the project. The single-story area is large and the floor height is high. There are many construction personnel, crossworking types of work, many three-dimensional operations, many professional subcontractors, and safety management is difficult; there are deep foundation pits and high floors. Major hazards such as formwork, overhanging scaffolding, and large hoisting machinery require high safety technical requirements; at the same time, the project is located in the prosperous area of Wucaicheng business district, and civilized construction and on-site image are essential; In addition, the project is adjacent to the hospital, the protection of the surrounding environment is of great significance. 


\subsection{Need for cost management}

This project involves a wide range of specialties, many subcontractors, and cross-operations between different construction processes, which makes a relatively high demand for cost management. In the construction process, it is difficult to guarantee the timeliness of material purchases, and it is impossible to avoid material waste or material shortages, if we grasp the material consumption and the construction progress only by manual statistics. To save costs, we need better management measure.

\section{Application and Innovation Research of BIM Technology in Project}

By careful analysis of the key and difficult problems in the construction of the project, combined with the advantages and characteristics of BIM technology, we can find that most of the key and difficult problems that need to be paid attention to in the construction can be solved or improved by means of BIM technology. Next, we focus on the application and innovation of BIM technology in the project.

\subsection{Application of BIM technology in construction organization}

(1) Application of "5D simulation and dynamic control technology"

To solve the problems in the construction organization process, BIM model is integrated with key information such as schedule, budget, resources and construction organization to actualize 5D application of BIM technology, which we called " $5 \mathrm{D}$ simulation and dynamic control technology", and to provide accurate information such as resource consumption and technical requirements for material, business, schedule, production and other important links in the construction process. Through simulation technology, reasonable arrangement of turnover of personnel, equipment, materials and tools before construction, planning of on-site transportation path, effectively solve the problems of material shortage, on-site transportation unchanged and professional coordination difficulties, ensure smooth flow construction, save cost and improve the level of project management, as shown in figure2.

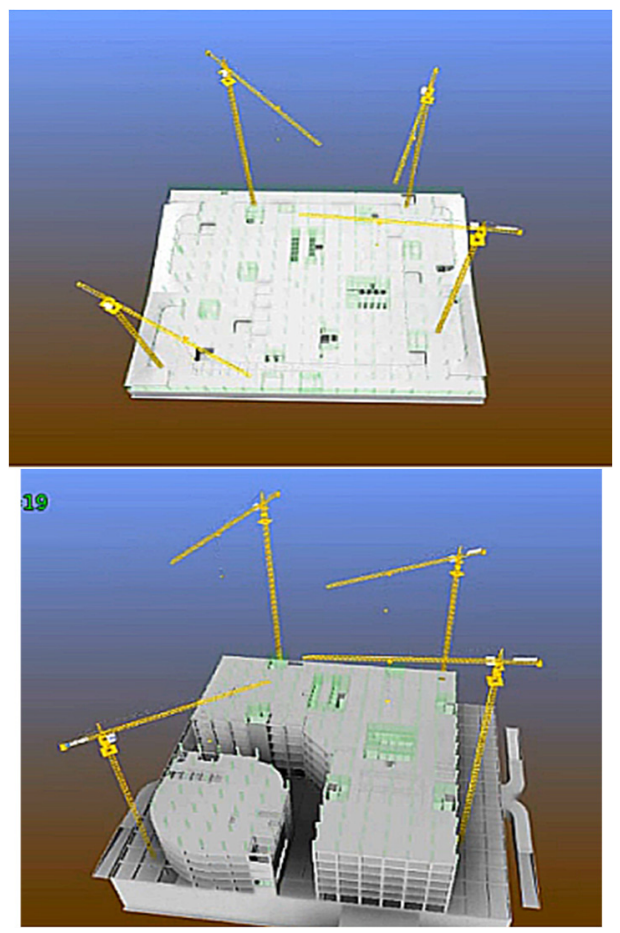

Fig 2. 5D simulation and dynamic control

(2) Construction plan simulation and clarification

Drawing up the construction plan with the help of BIM technology, changing the plan from plane understanding to three-dimensional visual observation, and then matching the process simulation, the logical relationship between each construction step and construction procedure can be displayed intuitively, which can help the manager to master the construction situation in an allround way, as shown in figure3.
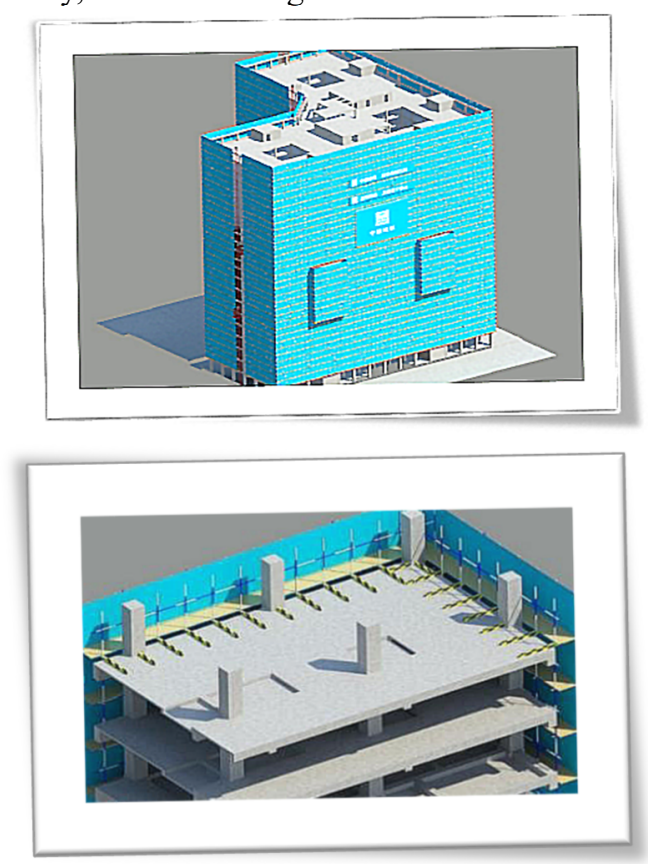

Fig 3. Construction plan simulation and clarification

\subsection{Application of BIM technology in deepening design management}

In this project, BIM technology was used in many aspects to deepen designs, such as in joint optimization design of 
steel structure, in bricklaying, in Mechanical and Electrical Installation and in establishing 3D models for complicated clinic. In this article, the author takes joint design as an example.

Because some steel structures and reinforcement joints in the original design of this project are relatively complex, which is not conducive to construction; in addition, some joints are complex in structure and have no corresponding 3D model auxiliary expression, which makes it difficult for construction workers to understand, and through the use of BIM technology to assist the joint optimization design of steel structures and steel bars to achieve the purpose of convenient site construction.as figure 4, by using BIM technology to optimize stirrups layout type, convenient site construction; as figure 5, by establishing steel bar and steel structure, connecting node model, make complex node visualization, to guide the field reinforcement binding.

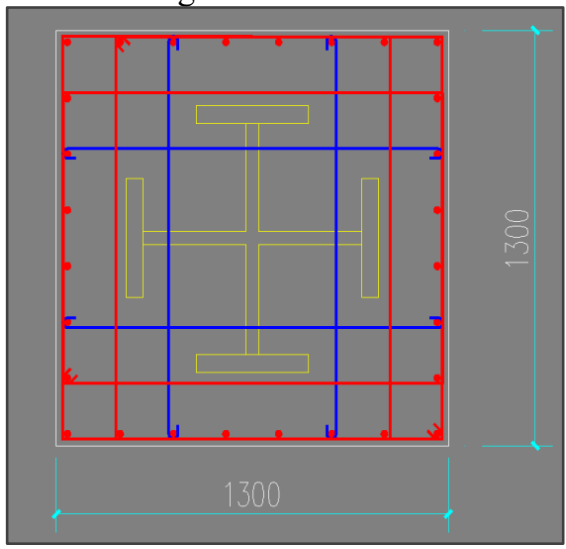

(a) Original design stirrups type

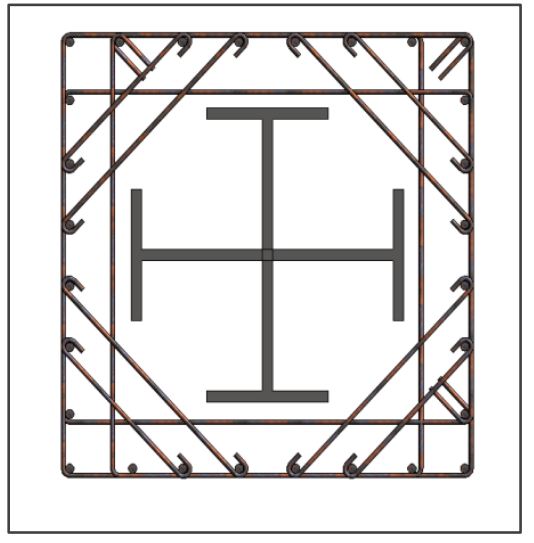

(b) Optimal design stirrups type

Fig 4. BIM Technical optimization of stirrups layout

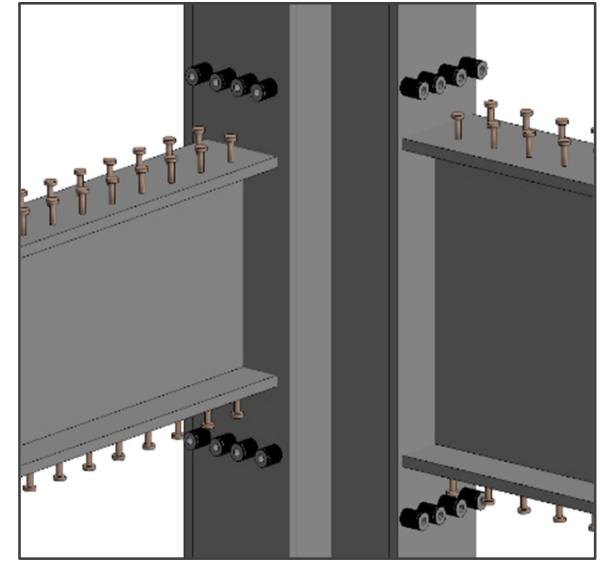

(a) Before

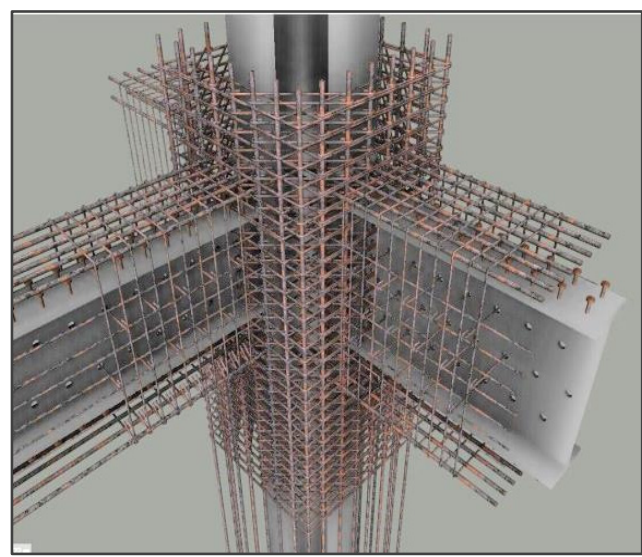

(b) connecting with steel bar

Fig 5. Establishment of joint model of steel structure and steel bar using BIM technology

\subsection{Application BIM technical quality management}

(1) Original design verification and review

By establishing the BIM model, we can find the problems of "wrong, leak, touch, missing" in the drawing intuitively. For example: the B1 layer drainage pipeline, laid according to the original design elevation and slope, will lead to the pipeline through the beam problem, such as late installation to reduce the elevation, may also lead to the drainage pipeline and municipal external network interface inverted slope problem, the original design need to be re-checked, as shown in figure 6 . 


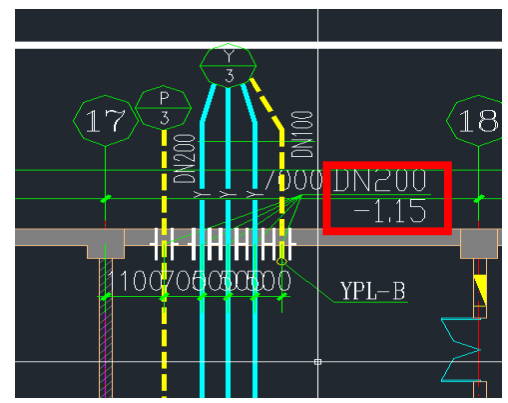

(a)The reserved level of pipeline in original design

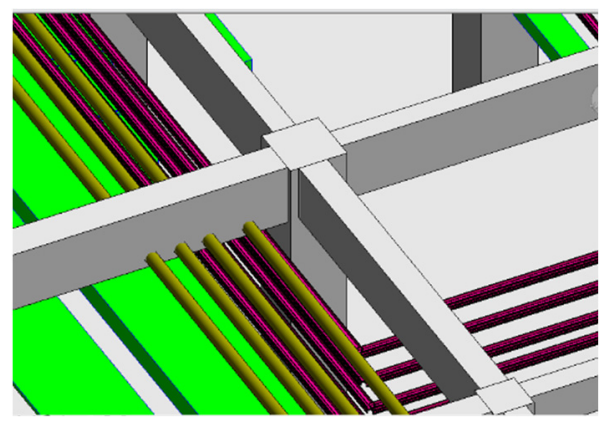

(b) According to the original design level and slope, the pipeline will cross the beam

Fig 6. Original design check and review

Quality information management

The BIM structure model is established by Autodesk Revit software, and then the model is imported into the Navisworks software to link to the external quality acceptance data, such as linking the BIM model to the concrete strength inspection and evaluation standard, extracting the bill of quantities through the BIM model, and determining the inspection batch directly according to the concrete strength inspection and evaluation standard, as shown in figure 7 .

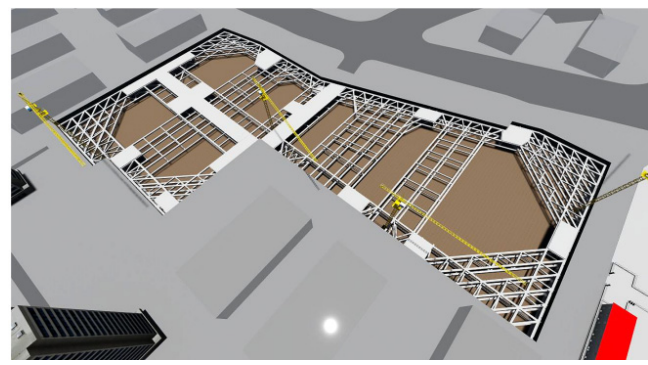

Fig 7. Quality information management based on B IM technology

\subsection{Cost management BIM application}

By means of BIM technology, engineering managers can classify and extract engineering quantities according to different types of engineering parts or materials with the progress of the project, provide data information for material procurement in the construction process, ensure the timeliness of material procurement, and facilitate cost management. For example, in the process of fine decoration in the inpatient department, managers can extract the list of materials from the BIM model, purchase materials, and master the real-time construction cost, as shown in figure 8.

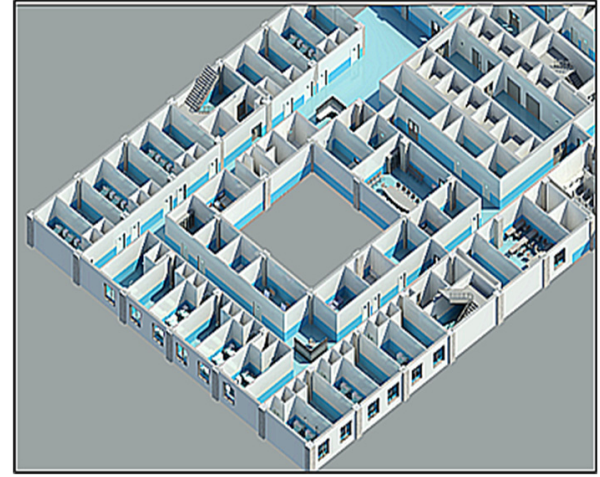

(a) Fine Decoration Drawing of Hospital Department

\begin{tabular}{|c|c|c|c|c|c|c|c|}
\hline \multirow[b]{2}{*}{ Number } & \multirow[b]{2}{*}{ Project } & \multirow{2}{*}{ Quantity } & \multirow{2}{*}{$\begin{array}{r}- \\
\text { Unit }\end{array}$} & \multicolumn{4}{|c|}{ Comprehensive unit price } \\
\hline & & & & $\begin{array}{l}\text { Materials } \\
\text { price per } \\
\text { unit }\end{array}$ & $\begin{array}{c}\text { Artificial } \\
\text { cost }\end{array}$ & $\begin{array}{l}\text { Taxes } \\
(3 \%)\end{array}$ & $\begin{array}{c}\text { Tax } \\
\text { included } \\
\text { subtotal }\end{array}$ \\
\hline & $\begin{array}{l}\text { Hetope } \\
\text { Engineering }\end{array}$ & & & & & 0.00 & 0.00 \\
\hline 7 & $\begin{array}{l}\text { Lump material } \\
\text { metope }\end{array}$ & 16.68 & $m^{2}$ & & 210.00 & 6.30 & 216.30 \\
\hline 8 & Emulsioni paint & 55.18 & $\mathrm{~m}^{2}$ & $\longrightarrow$ & 28.70 & 0.86 & 29.56 \\
\hline 9 & $\begin{array}{l}\text { Concealed door of } \\
\text { fire box }\end{array}$ & 1 & & 191.00 & 220.00 & 12.33 & 423. 33 \\
\hline 10 & Decorative wall & 0.9 & $\mathrm{~m}^{2}$ & 155.00 & 118.50 & 8.21 & 281.71 \\
\hline 11 & $\begin{array}{l}\text { Spain beige stone } \\
\text { frame mantle line }\end{array}$ & 1.03 & $m^{2}$ & 770.00 & 135.00 & 27.15 & 932.15 \\
\hline 12 & Decorative sheet & 1.14 & $\mathrm{~m}^{2}$ & 91.90 & 100.00 & 5.76 & 197.66 \\
\hline 13 & \begin{tabular}{|l|} 
Decorative \\
picture
\end{tabular} & 1 & & $2,000.00$ & 50.00 & 61.50 & $2,111.50$ \\
\hline 14 & $\begin{array}{l}\text { Stone elevator door } \\
\text { mantle line }\end{array}$ & 6.64 & $m^{2}$ & 512.00 & 135.00 & 19. 41 & 666.41 \\
\hline 15 & $\begin{array}{l}\text { Elevator door } \\
\text { upside tile }\end{array}$ & 0.81 & $\mathrm{~m}^{2}$ & & 79.50 & 2. 39 & 81.89 \\
\hline
\end{tabular}

(b) Project quantity extraction

Fig 8. Application of BIM technology in cost management

\subsection{Application of BIM Technology in Safety Management}

The traditional safety management in construction, generally through the assumption of possible safety risks before construction, so as to formulate the corresponding safety management system, but the construction site situation is complex, with the progress of the construction process, the situation will be different, so it is impossible to fully predict the possible hidden dangers before construction, resulting in frequent accidents. This project through the establishment of engineering entity model, and then with the help of roaming simulation function, with the progress of construction, real-time search for the possible safety hidden dangers in the project site, targeted security protection deployment, the establishment of a protection system, effectively avoid the occurrence of security hidden dangers, as shown in figure 9. 


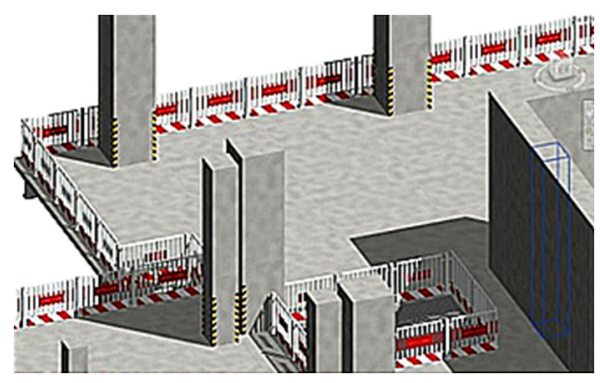

(a) Border Protection

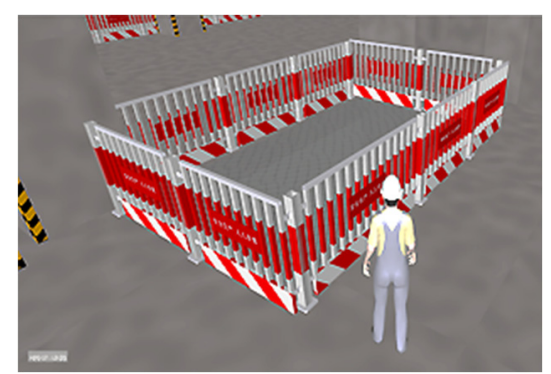

(b) Hole Protection

Fig 9. Application of BIM Technology in Safety Management

\section{Conclusions}

By introducing BIM technology in the construction management stage of the project, the construction safety and construction quality of the project have been ensured, the quality problems and design defects have not been found in the years when the hospital was put into operation, the quality and safety objectives set at the beginning of the project construction have been completed, and the "Luban Award for China Construction Project" has been obtained. In addition, through the application of B IM technology in data management, construction process simulation and design bottom, the project has achieved good economic benefits of up to 910,000 yuan. In addition, the construction organization is optimized based on B IM technology to save the construction period. All in all, applying BIM technology to the construction management stage of medical project can avoid the problems of design defect, quality hidden trouble and economic loss caused by its complex process to the greatest extent, and the application effect is remarkable.

\section{Acknowledgement}

Fund projects: 2018 Science and Technology Innovation Project of Dalian Vocational \& Technical College; 2019 Scientific Research and Innovation Fund Program of Dalian Vocational and Technical College (Serial Number: DZ2019CXJJ03).

\section{References:}

1. Zhou Guixiang, Jiang Fengchang, etc. BIM Application of Science and Education Complex Building in Shanghai Chest Hospital. Industrial Architecture 2018,48(2):47-52.
2. Application of BIM in construction and operation management of medical buildings. Construction economy, 2018, 39(2):40-44.

3. Gu Xiangdong etc. Application of BIM technology in the whole life cycle of hospital construction project. Construction economy, 2018, 39(1):49-52.

4. Dai Lei, etc. Comprehensive Application of Engineering B IM Technology in the First People's Hospital of Suqian City. Engineering Construction ,2018,19:88-91

5. Mer schbrock C,Munkvold B E.Effective digital collaboration in the construction Industry A case study of BIM deployment in a hospital construction project[J]. Computer in Industry,2015(2):1-7

6. Nordic Construction, Ratio Construction, St. Olaf Hospital, Trondheim, Norway, New Norwegian Architecture ,2017,6:42-49 